\title{
Retrospective Evaluation of Determinants of Road Traffic Injuries at a Naval Station
}

Tripti Agrawal ${ }^{1}$, Sandeep Kumar Sinha ${ }^{2}$, Nitesh Agrawal ${ }^{3}$

${ }^{1}$ Community Medicine, Health Officer Jalandhar Cantt, Punjab; ${ }^{2}$ Community Medicine, PMO INHS Ashwini; ${ }^{3}$ Anesthesia and Critical Care, MH Jalandhar cantt, Punjab

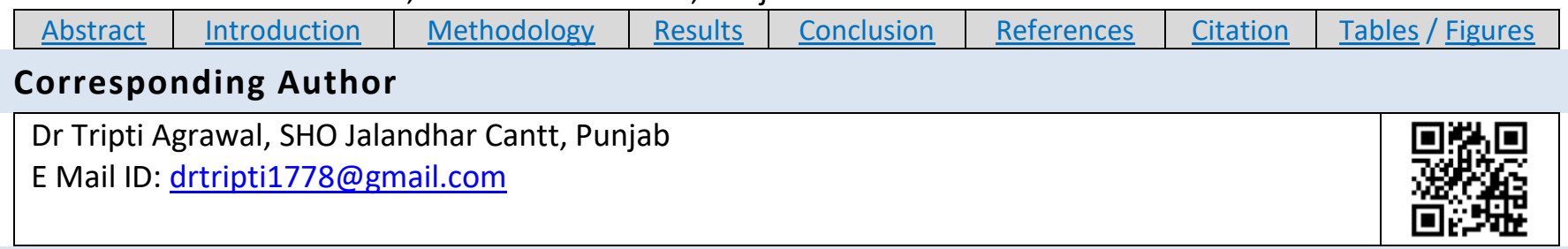

\section{Citation}

Agrawal T, Sinha SK, Agrawal N. Retrospective Evaluation of Determinants of Road Traffic Injuries at a Naval Station.Indian J Comm Health. 2021;33(1):205-211. https://doi.org/10.47203/IJCH.2021.v33i01.030

Source of Funding: Nil Conflict of Interest: None declared

\section{Article Cycle}

Received: 30/11/2020; Revision: 15/12/2020; Accepted: 09/01/2021; Published:31/03/2021 This work is licensed under a Creative Commons Attribution 4.0 International License.

\section{Abstract}

Introduction: Several factors like globalization, industrialization, migration, access to modern ways of living, increasing income levels, easy availability of vehicles, point of use entertainment/communication gadgets, media influence and others have brought human beings in close contact with a variety of challenges to safe driving, resulting in an increased occurrence of Road Traffic injuries across the globe. Methods and Material: A crosssectional descriptive study was conducted at naval station amongst victims of road traffic accidents who reported to emergency department of naval hospital over period of six months. Interviews on structured questionnaire to explore various determinants of road traffic injuries (RTI). Data Analysis on 156 victims was carried out for proportion of study variables of interest, Chi square test to determine significant differences between demographic variables and RTA exposure. Results: Of 156 RTA victims, more than 50\% were between 21 - 40 years; $69.9 \%$ were male; $93 \%$ accidents were contributed by driving speed more than $40 \mathrm{~km} / \mathrm{hr} ; 47 \%$ occurred at road junctions followed by civil roads; $27 \%$ were due to collision. $23 \%$ accidents took place on Saturdays; $36 \%$ were in morning 06 - 12 hours. 1/3 accidents were caused by two wheeler vehicles. Negligence of driver (40.4\%) poor road condition (24.4\%) were major causes of the accident as reported by victims. $44.2 \%$ of the victims had minor injury; $58.7 \%$ drivers who met accidents were holding valid driving license; $38 \%$ were wearing protective gears and $56 \%$ narrated that road lights/ traffic signals were available at vantage points. Exposure to accidents was found to be having statistically significant difference when related to age, gender, type of accident, common causes of accident and use of protective gears. Conclusions: The stricter application of traffic laws and safety measures are required to bring down the road traffic accident rate and related mortality.

\section{Keywords}

Road Point of Use Entertainment gadgets; Road Safety Education; Epidemiological Model

\section{Introduction}

Injuries resulting from road accidents have seen exponential rise in past two decades, especially in developing countries like India which demands immediate public health as well as legislative actions to control the peak. (1) It is evident that multiple factors like globalization, industrialization, migration, modern lifestyle, affordability, availability of motorized transportation, point of use entertainment/ communication gadgets, media influence etc had brought human beings in close contact with a variety of challenges to safe driving 
ending in an increased occurrence of Road Traffic Injuries (RTIs). $(2,3)$ The Global Status Report of WHO on Road Safety 2018 (4) mentions the total number of Road Traffic Accident (RTA) mortality figures were as high at 1.24 million per year and 3400 people die on the world's roads every day while in India alone, road traffic deaths per lac is 18.9 , maximum number $(38.7 \%)$ of deaths occurred by unspecified vehicle followed by two/three wheeler (32.4\%) vehicles. India has $1 \%$ of the world's vehicles, but $6 \%$ of the total global RTA deaths which may just be the tip of the iceberg and it may be 15-20 times the number killed. $(5,6,7)$

Road accidents are largely preventable since they are not often due to ignorance, but are due to carelessness, thoughtlessness and over confidence. William Haddon, Head of Road Safety Agency, USA has already highlighted that Road safety is associated with numerous issues, each of which needed to be addressed separately(8). Recent judicial engagement and directives (9) is a welcome sign; however implementation of the same to save lives, remains to be seen. Accidents, therefore have to be studied in terms of an epidemiological model i.e. agent, host and environmental factors and analyzed in relation to time, place and person distribution. (10) This study is therefore an attempt to explore various determinants of road traffic injuries by retrospective evaluation of inputs from personalized interviews, case sheets and medico legal records of road traffic accidents reporting to emergency care department of a zonal hospital at a naval station.

\section{Aims \& Objectives}

1. To identify the various determinants of road traffic injuries in a station

2. To recommend the road safety measures to overcome risk factors predisposing to road traffic accidents.

\section{Material \& Methods}

A cross-sectional study was conducted at a naval station amongst the victims of road traffic accidents who reported to the emergency department of the naval hospital over a period of six months from Sep 19 to Feb 20. Only respondents who agreed and gave their informed consent were included in the study. Confidentiality of the study participants were ensured before enrolling them. Institutional approval was taken from the ethical committee of the hospital. Victims were those who injured by any motorized vehicles, whether driving the vehicle or co-passengers or pedestrian hit by the vehicle causing accident. Further, respondents who were unable to speak and have fatal injuries, the response of their accompaniments were recorded in order not to loose the data on risk factors responsible for fatalities. Interviews on a structured questionnaire were carried out separately in a suitable setting in the hospital, commonly where the respondent felt comfortable, by the investigator himself.

The World Health Statistics 2011(1) has revealed $8.8 \%$ of total mortality due to injuries and out of total $90 \%$ contributed by RTI. Hence, total burden of RTI is $7.92 \%$. With this reference, the sample size was calculated as 111 . In the present study data was gathered on 156 victims, including drivers or co passengers who reported to emergency care over duration of 6 months.

Data Analysis was carried out for the proportion of the study variables of interest, Chi square test to determine significant differences between demographic variables and RTA exposure. SPSS version 20 software was used.

\section{Results}

More than half $(66.4 \%)$ of the victims represented the age group $\geq 30 \mathrm{yrs}$. $69.9 \%$ of the victims were male, half of the victims were educated from secondary to higher secondary level and $40.4 \%$ were dependants of serving while $31.4 \%$ were serving personnel. The study documents that $93 \%$ of accidents were contributed by driving speed more than $40 \mathrm{~km} / \mathrm{hr}$; most (47\%) of the accidents occurred at road junctions followed by civil roads, out of which $27 \%$ were due to collision between vehicles followed by $18.7 \%$ were due to collision with pedestrians. (Table 1) shows that the highest number of accidents took place on Saturdays (23\%), while maximum (36\%) of the accidents were in the morning $(6.00 \mathrm{am}$ - $12.00 \mathrm{pm}$ ) time followed by $31.2 \%$ in between 12.00 $\mathrm{pm}$ to $6.00 \mathrm{pm}$. Nearly one third $(32.7 \%)$ of the accidents were caused by two wheeler vehicles, followed by $18 \%$ were cyclist/auto rickshaw and $16.6 \%$ were four wheeler/ other heavy vehicle. $21.2 \%$ of victims were passenger and $11.5 \%$ were pedestrians. However, negligence of driver (40.4\%) and poor road condition (24.4\%) were the major causes of the accident as reported by the victims. Talking on mobile was found to be the commonest (20.5\%) driver related causal factor followed by careless attitude to defensive driving was the next quoted factor. Findings showed that $44.2 \%$ of the 

victims had minor injury, $32 \%$ had moderate and $23.8 \%$ had severe injury. The patterns of injuries among victims were as follows: maximum number (30.1\%) of the victims had superficial injuries, followed by $24.4 \%$ had fractures $19.2 \%$ reported thoracic injuries, $15.4 \%$ had head injuries, $13.5 \%$ had abdominal injury and $11.5 \%$ had spinal injuries. Among the total fractures, lower extremities were the commonest site. $58.7 \%$ of drivers who met accidents were holding valid driving license; $38 \%$ were wearing protective gears viz helmets, seatbelts, and $56 \%$ narrated that road lights/ traffic signals were available at vantage points. (Table 2 ) shows the association of risk factors with severity of accident exposure amongst RTIs victims. Exposure to accidents was found to be having statistically significant difference when related to age, gender, type of accident, common causes of accident and use of protective gears with $p$ value less than 0.05 . while results was found not to be significantly associated with days of the week, average driving speed, mode of travel during accident, holding valid driving license.

\section{Discussion}

RTIs as evident from existing literature mainly affects the younger generation of productive age bracket adversely affecting future manpower resources of the country. State and region wise difference exist in prevalence and incidence of road accidents, injuries and deaths attributable to socio-economic, cultural, demographic, topographical differences and notification practices. The multitude impact of road accidents on individual, family and society in terms of morbidity, disability, economic and social fall out is immense and remains under recognized. $(5,10)$ The present study elaborates the potential socioeconomic-behavioral-epidemiological risk factors for road traffic injuries with an attempt to establish association of these risk factors with severity of road traffic accident exposure amongst RTI victims. The study found out statistically significant association with age less than $30 \mathrm{yrs}$, male gender, type of accident, cause of accident, use of protective gears. Similar results were corroborated with earlier studies. (3,5,7-13) Exposure to accidents was found not to be significantly associated with days of the week, average driving speed, mode of travel during accident, holding valid driving license.

In the present study, age group of $20-40$ years was maximally affected being enthusiastic, tendency to over speed, lesser years of driving experience, career constraints and greater mobility due to studies or employment. Lower proportions of accidents were reported in above 60 years and above could be due to the generally lesser mobility of the people. In the present study, the accident rates were 4.3 times higher amongst males than females and similar results were found in few other studies as well $(11,12,13)$. Amongst the victims, two wheelers followed by pillion riders/passengers, cyclist/auto rickshaws, pedestrians and four wheelers/ heavy duty vehicles. It is interesting to note that among the type of vehicles, motor cycle and auto rickshaw were involved in the highest number of accidents. This could be due to the higher speed, which can be achieved over short distances and less stability of the vehicle. Bicycle riders appear to be at greater risk of sustaining injury amongst non-motorized transport. Rough driving, over speeding and vehicles offering poor controls are the possible reasons as suggested by victim's interviews. The usage of helmets, seatbelts, driving lights in this study (which includes non-fatal cases) was above $38 \%$ and was shown to be protective. The findings of present study corroborate with findings of study by Solanki et al (14) revealing lower incidence as well as severity of injuries in individuals who used protective gears. Study by Kiran et al (15) showed that maximum accidents occurred between $18.00-24.00 \mathrm{hr}$ while in the present study maximum accidents took place between 06.00$12.00 \mathrm{hr}$. In another study conducted by Jha et al (16) in Puducherry, the peak time observed was between 16.00 - $19.00 \mathrm{hr}$ however present study findings matches with study out by Verma et al (17) in Central India. The slight difference in timings as compared to the present study can be due to difference in work culture (and hence peak hours). In cases, where collision occurred with another vehicle, collision between vehicles was the commonest type $(27 \%)$ collisions with pedestrian, sideways collision, fell down/skid, hit and run, rash driving and animal obstruction. It was found that, at most turnings the warning sign boards were missing.

Among the serious injuries, lower limb fractures were the commonest followed by head injuries. The most severe injuries suffering category was that of "occupants of motorized two-wheelers". This is explained by the fact that motorized two-wheelers have triple risk. Firstly they are uncovered; secondly they are relatively unstable and thirdly there is a tendency to ride them at higher speeds. This all 
amounts to an impact of greater mechanical energy during the accident which leads to injuries that most of the times are severe. Headgear had a protective effect on head injuries. This study found $41.3 \%$ drivers of different vehicles were without driving license. The reason may be the easy accessibility of the vehicles, usually youngster at home and the casual attitude of driving besides lesser experience. In the present study, $5 \%$ of the drivers involved in RTA had consumed alcohol. The role of alcohol in impairing driving ability is well documented. Similar results were found in few other studies as well. (11-

\section{7)}

High Income Countries of the world till early 1970's had witnessed similar trends of road traffic injuries. Subsequently many countries turned this scenario and developed, implemented, monitored and evaluated road safety activities by putting strong systems in place to overcome challenges and barriers in road safety (4). The results are there in front of us as seen by continuous decline in road deaths and injuries in most countries of the world. Few countries in the world are moving towards Vision Zero with the vision that no one should die on roads. (1)

Although existing data from national registry indicates the ever increasing burden and impact of road crashes but efforts to address the problem is still far from satisfactory. Our growing graph indicates that our ongoing efforts are insufficient or our efforts are mis-prioritised and misdirected. Lack of central and state lead agencies, limited funding, poor coordination mechanisms, limited impact of laws, laxity in enforcement, limited safety features on roads and in vehicles, deficient trauma care coupled with absence of public engagement are a few problems plaguing our systems. $(2,10)$

The Motor Vehicles Amendment Bill 2016 is a landmark step in this direction. Several judicial directives in recent times are aimed at strong actions to be taken by governments. The implementation of these key steps will be an urgent necessity to improve the current scenario. This calls for participation of all key stakeholders in different ministries, industry, academia and civil society to develop coordinated and convergent actions to advance road safety in India. The five years of the Bangalore Road Safety Programme is a readymade integrated model to be replicated. The Centre's contribution to helmet legislation, reduction of drink
$\&$ drive, pedestrian safety and post-crash care are well known and are built on data-driven programmes. (10) The United Nations Decade for Road Safety (2011-2020) advocates application of "five pillars" (Road safety management, safer road infrastructure, safe vehicles, safer road use behavior and post-crash care) as a framework to reduce road accidents and deaths globally. (4)

\section{Conclusion}

There is clearly a requirement for road safety education which should be directed towards road users, who are frequently involved and injured in RTAs. Thus stricter application of traffic laws and safety measures are required to bring down the road traffic accident rate and related mortality. Helmets and seatbelts have a significant role in preventing severe head injuries and highly advocated. Concrete measures need to be taken for pedestrian and bystander safety. Well-equipped adequately staffed trauma centers should be dedicated to managing limb and life threatening road traffic injury victims. Time is ripe to rethink our strategies to beat challenges and focus on creating a road safety revolution in the country.

\section{Recommendation}

This study solicits the emphasis by parents, guardians, school and licensing authorities on high school students, the future generation which is soon going to qualify the legal age bar to drive on roads, to be oriented to understanding the mechanics of braking distance, defensive driving and hazards of substance abuse especially while driving any motorized vehicle. Road side random breath testing for alcohol should be done by using breath analyzers, which is proxy indicator of blood concentration level of alcohol. The licensing authorities have a very important role to play in development of appropriate driving skills by adopting stricter, more comprehensive and scientifically based test laying a stress on road rules, regulations and traffic control devices. At the time of giving license to the public transport drivers (Bus and Trucks), they can be trained in first-aid skills so that victims are attended immediately in the post-accident period.

\section{Limitation of the study}

Data in case of respondents who were unable to speak and have fatal injuries was collected from their accompaniments with the purpose of not to loose the data on risk factors responsible for fatalities. 


\section{Authors Contribution}

TA: Study protocol \& Methodology, Data Collection, Data Analysis, Manuscript Writing. SKS: Conceptualisation, Investigation, Project Administration, Manuscript review. NA: Ethical clearance, Funding acquisition, Manuscript review and editing

\section{References}

1. National Burden of Disease Studies. World Health Organisation. Available on https://www.who.int , healthinfo > nationalburdenofdiseasemanual. [Accessed on 02 Feb 2021].

2. National Crime Review Board Report India. Available on www.ncrb.gov.in , StatPublications , ADSI > ADSI2018 , chapter-1. [Accessed on 02 Feb 2021].

3. Pathak SM, Jindal AK, Verma AK, Mahen A. An epidemiological study of road traffic accident cases admitted in a tertiary care hospital. Med J Armed Forces India. 2014;70(1):32-5. doi: 10.1016/j.mjafi.2013.04.012. Epub 2013 Aug 30. PMID: 24623944; PMCID: PMC3946410.[PubMed]

4. Global Status Report on Road Safety 2018. World Health Organisation. Available on https://www.who.int/violence injury prevention/road sa fety status/2018. [Accessed on 02 Feb 2021].

5. Gururaj G. Road traffic deaths, injuries and disabilities in India: current scenario. NatI Med J India. 2008;21(1):14-20. PMID: 18472698. [PubMed]

6. Mohan VR, Sarkar R, Abraham VJ, Balraj V, Naumova EN. Differential patterns, trends and hotspots of road traffic injuries on different road networks in Vellore district, southern India. Trop Med Int Health. 2015;20(3):293-303. doi: 10.1111/tmi.12436. Epub 2014 Dec 16. PMID: 25425088; PMCID: PMC4308433.[PubMed]

7. Madan VS. Road Traffic Accidents: Emerging Epidemic. Indian Journal of Neurotrauma. 2006;3(1):1-3
8. Gururaj G, Gautham M S. Advancing Road Safety in IndiaImplementation is the Key, Bengaluru, 2017. National Institute of Mental Health \& Neuro Sciences; 2017. Publication Number : 136.

9. The Motor Vehicles (Amendment) Bill. The Economic Times 2019 Jul 31; Sec A2(col5)

10. Gupte MD, Ramachandran V, Mutatkar RK. Epidemiological profile of India: historical and contemporary perspectives. J Biosci. 2001;26(4 Suppl):437-64. doi: 10.1007/BF02704746. PMID: 11779959.[PubMed]

11. Pal R, Ghosh A, Kumar R, Galwankar S, Paul SK, Pal S, Sinha D, Jaiswal AK, Moscote-Salazar LR, Agrawal A. Public health crisis of road traffic accidents in India: Risk factor assessment and recommendations on prevention on the behalf of the Academy of Family Physicians of India. J Family Med Prim Care. 2019;8(3):775-783. doi: 10.4103/jfmpc.jfmpc_214_18. PMID: 31041200; PMCID: PMC6482791.[PubMed].

12. Singh SK. Road Traffic Accidents in India: Issues and Challenges. Article in Transportation Research Procedia. 2017;25:212-216

13. Mishra B, Sinha Mishra ND, Sukhla S, Sinha A. Epidemiological study of road traffic accident cases from Western Nepal. Indian J Community Med. 2010;35(1):11521. doi: 10.4103/0970-0218.62568. PMID: 20606934; PMCID: PMC2888338. [PubMed]

14. Solanki HL, Mittal H. An Epidemiological Study of Road Traffic Accident Cases at a Tertiary Care Hospital in Udaipur.Int J Cur Res Rev.2016; 8(7):32-36.

15. Kiran R,MuralidharK,Vijaya K. Prospective Study on Road Traffic Accidents. JPAFMAT. 2004;4:11-16

16. Nilambar Jha, Srinivas DK, Gautam Roy, Jagdish S. Epidemiology of Road Traffic Accident cases: A study from South India. Indian Journal of Community Medicine.2004; 29(1):20-24.

17. Verma P, Gupta SC, Kaushal M, Singh G. National Journal of Community Medicine.2015;6(2):354-358

\section{Tables}

\begin{tabular}{|c|c|c|}
\hline Study Variable & n (\%) & $95 \% \mathrm{Cl}$ \\
\hline \multicolumn{3}{|l|}{ Day of accident } \\
\hline Monday & $25(16 \%)$ & $(20.8-29.2)$ \\
\hline Tuesday & $18(11.5 \%)$ & $(14.4-21.6)$ \\
\hline Wednesday & $22(14 \%)$ & $(18.2-25.8)$ \\
\hline Thursday & $13(8.3 \%)$ & $(10.5-15.5)$ \\
\hline Friday & $23(14.7 \%)$ & $(19.1-26.9)$ \\
\hline Saturday & $36(23 \%)$ & $(33.1-38.9)$ \\
\hline Sunday & $19(12.5 \%)$ & $(14.8-23.2)$ \\
\hline \multicolumn{3}{|l|}{ Time of accident } \\
\hline$>00.00-06.00 \mathrm{hr}$ & $18(11.6 \%)$ & $(14.6-21.4)$ \\
\hline$>06.00-12.00 \mathrm{hr}$ & $56(35.9 \%)$ & $(50.9-61.1)$ \\
\hline$>12.00-18.00 \mathrm{hr}$ & $47(30 \%)$ & $(43.4-50.6)$ \\
\hline$>18.00-24.00 \mathrm{hr}$ & $35(22.5 \%)$ & $(30.4-39.6)$ \\
\hline \multicolumn{3}{|c|}{ Mode of travel during accident } \\
\hline Bike/scooter rider & $51(32.7 \%)$ & $(45.6-56.4)$ \\
\hline Passenger or pillion rider & $33(21.2 \%)$ & $(28.6-37.4)$ \\
\hline Pedestrian & $18(11.5 \%)$ & $(15.2-20.8)$ \\
\hline
\end{tabular}


INDIAN JOURNAL OF COMMUNITY HEALTH / VOL 33 / ISSUE NO 01 / JAN-MAR2021

[Retrospective Evaluation...] | Agrawal T et a

Cyclist/Auto rickshaw

Four wheeler\&Other Heavy Vehicle

$8 \%)$

$(24.2-31.8)$

Causes of accident

Driver's fault/negligence

$26(16.6 \%) \quad(22.2-29.8)$

Poor vehicle condition

$63(40.4 \%)$

Road factor

Others

\section{Driver related causal factors $(n=63)$}

Talking on mobile

Listening music

Drug Addiction

$25(16 \%)$

$(59.4-66.6)$

$38(24.4 \%)$

$(21.2-28.8)$

$30(19.2 \%)$

$(33.8-42.2)$

Smoking/ tobacco chewing

Alcohol consumption

Associated medical illness/ personal condition

Careless attitude

Severity of Injury

Minor

Moderate

$13(20.5 \%)$

$7(10.0 \%)$

$5(7.7 \%)$

$(26.8-33.2)$

Severe

Site of Injury

Head Injury

Fractures

Spinal Injury

Superficial Injury/sprain

Abdominal Injuries

$11(18 \%)$

$9(13.5 \%)$

$8(12.7 \%)$

$10(17.6 \%)$

$(10.3-15.7)$

$(5.5-8.6)$

$(4.1-5.9)$

$(9.2-12.8)$

$(7.1-10.9)$

$(7.2-8.8)$

$(8.6-11.4)$

Thoracic Injuries

Holding Valid Driving License (105)

Yes

No

Use of Protective Gears (105)

Yes

No

$69(44.2 \%)$

$(64.1-73.9)$

$50(32 \%)$

$(44.8-55.2)$

$37(23.8 \%)$

$(34.4-39.6)$

\begin{tabular}{l|l}
\hline $24(15.4 \%)$ & $(21.6-26.4)$ \\
\hline $38(24.4 \%)$ & $(33.2-42.8)$ \\
\hline $18(11.5 \%)$ & $(15.4-20.6)$ \\
$47(30.1 \%)$ & $(43.6-50.4)$ \\
\hline $21(13.5 \%)$ & $(18.2-23.8)$ \\
\hline $30(19.2 \%)$ & $(26.2-33.8)$ \\
\hline $62(58.7 \%)$ & $(54.9-62.5)$ \\
\hline $43(41.3 \%)$ & $(39.1-43.5)$ \\
\hline $40(38 \%)$ & $(35.2-40.8)$ \\
$65(62 \%)$ & $(58.6-65.4)$ \\
\hline $21(56 \%)$ & $(53.6-58.4)$ \\
$17(44 \%)$ & $(15.1-18.9)$
\end{tabular}

Availability of Road Lights/ Traffic signals (38)

Yes

No

$17(44 \%)$

$(15.1-18.9)$

TABLE 2 ASSOCIATION OF RISK FACTORS ASSOCIATED WITH SEVERITY OF ACCIDENT EXPOSURE TO RTI VICTIMS

\begin{tabular}{|c|c|c|c|c|c|}
\hline \multirow[t]{2}{*}{ Study Variable } & \multicolumn{3}{|c|}{ Severity of Injury } & \multirow[t]{2}{*}{ Chi square } & \multirow[t]{2}{*}{$p$ value } \\
\hline & $\begin{array}{c}\text { Minor } \\
(n=69)\end{array}$ & $\begin{array}{c}\text { Moderate } \\
\quad(n=50)\end{array}$ & Severe $(n=37)$ & & \\
\hline \multicolumn{6}{|l|}{ Age in years } \\
\hline$\leq 30$ yrs $(54)$ & 19 & 23 & 11 & \multirow[t]{2}{*}{4.8} & \multirow[t]{2}{*}{0.041} \\
\hline$\geq 30$ yrs (102) & 50 & 27 & 26 & & \\
\hline \multicolumn{6}{|l|}{ Sex } \\
\hline Male (109) & 51 & 28 & 30 & \multirow[t]{2}{*}{7.31} & \multirow[t]{2}{*}{0.026} \\
\hline Female (47) & 18 & 22 & 7 & & \\
\hline \multicolumn{6}{|l|}{ Days of the week } \\
\hline Weekdays & 46 & 33 & 23 & \multirow[t]{2}{*}{0.228} & \multirow{2}{*}{0.892} \\
\hline Weekends & 23 & 17 & 14 & & \\
\hline \multicolumn{6}{|l|}{ Average driving speed } \\
\hline$<40 \mathrm{~km} / \mathrm{h}(11)$ & 6 & 3 & 2 & \multirow{3}{*}{0.0485} & \multirow[t]{3}{*}{2.24} \\
\hline $40-60 \mathrm{~km} / \mathrm{h}(74)$ & 31 & 23 & 20 & & \\
\hline$\geq 60$ km/h (71) & 32 & 24 & 15 & & \\
\hline \multicolumn{6}{|l|}{ Mode of travel during accident } \\
\hline Bike/scooter rider (51) & 26 & 19 & 6 & \multirow[t]{2}{*}{9.69} & \multirow[t]{2}{*}{0.288} \\
\hline Passenger or pillion rider (33) & 12 & 10 & 11 & & \\
\hline
\end{tabular}




\begin{tabular}{|c|c|c|c|c|c|}
\hline \multicolumn{4}{|c|}{ INDIAN JOURNAL OF COMMUNITY HEALTH / VOL 33 / ISSUE NO 01 / JAN-MAR2021 } & [Retrospective Evaluation...] & \multirow[t]{4}{*}{ Agrawal T et } \\
\hline Pedestrian (18) & 8 & 5 & 5 & & \\
\hline Cyclist/Tri-wheeler (28) & 9 & 11 & 8 & & \\
\hline Four wheeler/ Heavy vehicle (26) & 14 & 5 & 7 & & \\
\hline \multicolumn{6}{|l|}{ Type of accident } \\
\hline Collision between vehicles (42) & 12 & 16 & 14 & \multirow[t]{6}{*}{9.31} & \multirow[t]{6}{*}{0.049} \\
\hline Collision with pedestrians (29) & 17 & 7 & 5 & & \\
\hline Sideways collision (23) & 9 & 7 & 6 & & \\
\hline Hit and Run (16) & 7 & 5 & 4 & & \\
\hline Fell down/skid (25) & 13 & 9 & 3 & & \\
\hline Animal obstruction (7) & 11 & 6 & 5 & & \\
\hline \multicolumn{6}{|l|}{ Causes of accident } \\
\hline Driver's fault/negligence (63) & 18 & 26 & 19 & \multirow[t]{4}{*}{25.5} & \multirow[t]{4}{*}{0.000} \\
\hline Poor vehicle condition (25) & 6 & 10 & 5 & & \\
\hline Road factor (38) & 19 & 12 & 7 & & \\
\hline Others (30) & 26 & 2 & 6 & & \\
\hline \multicolumn{6}{|l|}{ Holding Valid Driving License (105) } \\
\hline Yes (62) & 23 & 21 & 18 & \multirow[t]{2}{*}{1.39} & \multirow[t]{2}{*}{0.099} \\
\hline No (43) & 12 & 19 & 14 & & \\
\hline \multicolumn{6}{|l|}{ Use of Protective Gears (105) } \\
\hline Yes (40) & 21 & 11 & 8 & \multirow[t]{2}{*}{7.51} & \multirow[t]{2}{*}{0.023} \\
\hline No (65) & 17 & 26 & 22 & & \\
\hline
\end{tabular}

